\title{
A "SINCRONIA" OU A "SINERGIA" AMBIENTAL ESTRATÉGICA? UM ESTUDO DE PRÁTICAS AMBIENTAIS EM EMPRESA DO SETOR ALIMENTÍCIO
}

\author{
Sandra Mara Schiavi Bánkuti \\ Doutora em Engenharia de Produção pela Universidade Federal de São Carlos - UFSCAR \\ Professora da Universidade Estadual de Maringá - UEM \\ smsbankuti@uem.br \\ Ferenc Istvan Bánkuti \\ Doutor em Engenharia de Produção pela Universidade Federal de São Carlos - UFSCAR \\ Professor da Universidade Estadual de Maringá - UEM \\ fibankuti@uem.br
}

\section{RESUMO}

Dentro do novo contexto competitivo, questões relativas ao meio-ambiente ganharam destaque em termos estratégicos empresariais. Neste contexto, uma adequada gestão ambiental empresarial passa, então, a ter grande relevância. Diante de tamanha importância a discussão acerca do desempenho das organizações sob diferentes enfoques, passa a abordar não-somente a competitividade econômica, mas também a ambiental. O objetivo proposto neste trabalho é discutir ações ambientais estratégicas implantadas por empresa multinacional do setor de alimentos no Brasil. Para tanto, foram utilizadas informações secundárias e dados primários coletados da empresa. Os resultados do trabalho indicaram alinhamento entre estratégia e práticas ambientais na unidade de negócios em estudo, principalmente em decorrência de adequações às leis e normas. Apesar da sincronia, não se pode afirmar que a estratégia competitiva tem como um dos pilares a gestão ambiental, não caracterizando sinergia ambiental estratégica, ainda que ela faça parte do SGI, que é estratégico, as ações e melhorias ambientais não se mostram direcionadoras na unidade em estudo. Alguns fatores podem caracterizar tal situação, tais como a imposição de práticas ambientais top down; a carência de métodos de melhoria e projetos com objetivos específicos em resultados ambientais; a carência de inovações em produto e processo para melhorias ambientais; e a escassez de interação intraorganizacional entre agentes internos e interorganizacional ao longo da cadeia de suprimentos para melhorias ambientais.

Palavras-chave: Estratégia competitiva; Gestão ambiental; Indústria de alimentos; Práticas ambientais.

\section{THE "SYNC" OR "SYNERGY" STRATEGIC ENVIRONMENTAL? A STUDY OF ENVIRONMENTAL PRACTICES IN FOOD INDUSTRY COMPANY}

\begin{abstract}
Environmental issues have arisen within the business strategy field thus appropriate adequate business environmental management has become relevant, leading to discussion on organizational performance under different focuses and considering competitiveness in economic and environmental aspects. This papers aims to discuss strategic environmental activities in a multinational production unit in the Brazilian food sector through secondary and primary data (in loco interview). Results showed alignment between strategy and environmental activities specifically related to legal and regulatory compliances (through the imposition of an Integrated Management System - IMS - by the group). Despite synchrony business strategy is not supported by environmental management and lacks strategic environmental synergy. Environmental improvements are not driving factors in the studied company although they are part of an IMS and considered a strategic aspect. Some aspects can explain that situation, such as top down environmental imposition, the shortage of specific environmental procedures, the absence of product and process environmental innovations, and little inter-firm and intra-firm interactions for environmental improvements.
\end{abstract}

Keywords: Environmental management; Competitive strategy; Environmental practices; Food sector.

Revista de Gestão Social e Ambiental - RGSA, São Paulo, v. 5, n. 2, p. 112-125, mai./ago. 2011. 


\section{INTRODUÇÃO}

As atividades humanas e empresariais modificam características do meio ambiente. Recentemente, essa questão tem recebido atenção especial, tanto nos canais de comunicação quanto em discussões e fóruns internacionais. Diferentes grupos de interesse (stakeholders), tais como Governo, clientes e sociedade, começaram a se atentar para responsabilidade ambiental e a exigir das empresas postura apropriada, no que concerne ao meio ambiente (Weber, 1999). O Governo, por meio da imposição de leis mais rígidas relativas às atividades empresariais e suas interações com o meio ambiente; os clientes e sociedade, ao exigirem produtos, processos e serviços mais "limpos", ou seja, com menor impacto negativo ao meio ambiente.

No contexto empresarial, sabe-se que o meio ambiente é fonte de recursos produtivos, tais como matérias-primas, energia, solo, metais, etc. Além disso, o processo produtivo tem como resultado outputs desejados, ou seja, os bens e serviços pretendidos, e indesejados, tais como resíduos e poluição. Deve-se discutir o desempenho das organizações sob diferentes enfoques, abordando-se não-somente a competitividade econômica, mas também a competitividade ambiental. ${ }^{\mathrm{i}}$

Assim, a gestão ambiental tem feito parte do novo cenário competitivo empresarial. Neste âmbito, o desenvolvimento de estratégias ambientalmente corretas se deve aos seguintes fatores: (a) menor possibilidade de multas ambientais; (b) redução de custos; (c) a possibilidade de entrada em novos mercados; (d) incremento de receitas e (e) maior valor à marca.

Independentemente do setor em que a empresa ocupa ou da valoração que seu grupo de consumidores confere às organizações, produtos ou serviços ambientalmente mais adequados, a decisão de ser ambientalmente correta representa para empresa uma estratégia que deve ser considerada. A necessidade de atender a exigências ambientais é direcionada pela demanda de alguns stakeholders, tais como a sociedade, o Governo e os consumidores. Nas cadeias agroalimentares, tal consideração se faz relevante, visto que, por um lado, a legislação ambiental mais rigorosa implica em mudanças no cultivo e no manejo de animais, adoção de tecnologia no campo, alterações nos processos produtivos industriais e restrições no espaço de atuação (uso da terra e da água); por outro, a demanda por produtos ambientalmente corretos também se intensifica no Brasil.

A indústria de alimentos no Brasil desempenha um papel socioeconômico de destaque. Em 2008, o valor bruto da produção da indústria de alimentos no Brasil atingiu a cifra de $\mathrm{R}$ \$256,9 bilhões, o que corresponde a $16,6 \%$ do total da indústria de transformação; seu valor bruto da transformação foi equivalente a $13,5 \%$ do total da indústria de transformação para o mesmo período, o que indica sua relevância em termos de agregação de valor. Além disso, destaca-se que essa indústria ocupava, em 2008, mais de 1,3 milhões de pessoas (18,4\% do pessoal ocupado na transformação) (Ibge, 2008). Tais valores posicionam a indústria alimentícia como a primeira no ranking nacional.

Segundo estudo da Fiesp e do Ital (2010), as tendências da alimentação passam por questões socioambientais, em que fatores, tais como produção sustentável, redução do impacto ambiental, rotulagem ambiental e uso de produtos reciclados e recicláveis se tornam relevantes. Nesse sentido, processos realizados a partir de fontes renováveis, gestão de resíduos e emissões, certificações e selos ambientais, processos produtivos sustentáveis e mais eficientes, entre outros aspectos, passam a ser mais valorizados. Inovações em produto e processo se tornam impulsionadoras de estratégias empresariais, à medida que permitem o uso mais eficiente de recursos, podendo alavancar a agregação de valor e o alcance de vantagens competitivas (Fiesp; Ital, 2010).

Considerando a relevância de atividades ambientais para competitividade empresarial, bem como as tendências da indústria de alimentos no Brasil, o objetivo proposto neste trabalho é a identificação e análise de estratégias ambientais implantadas por empresa de capital nacional atuante no setor em questão. Para tanto, além desta introdução, este trabalho é composto pelas

Revista de Gestão Social e Ambiental - RGSA, São Paulo, v. 5, n. 2, p. 112-125, mai./ago. 2011. 
seguintes seções: (a) método empregado no trabalho; (b) revisão teórica; (c) discussão dos resultados, com caracterização da empresa e análise do caso; (d) considerações finais; e (e) referências.

\section{MÉTODO DE PESQUISA}

Para que os objetivos deste trabalho pudessem ser cumpridos, foi realizada pesquisa de caráter qualitativo, utilizando, como instrumento, o método de estudo de caso em uma unidade de negócios de uma empresa multinacional do setor de alimentos.

$\mathrm{O}$ intuito foi verificar em quais aspectos as atividades de cunho ambiental, desenvolvidas pela empresa, estavam relacionadas com a competitividade, considerando o alinhamento com questões estratégicas, a interação entre as áreas empresariais, as dificuldades e os resultados alcançados.

Para tanto, foram empregados os seguintes procedimentos: (a) revisão de literatura sobre gestão ambiental, sistemas de gestão ambiental e estratégias competitivas; (b) elaboração e aplicação de roteiro de entrevista em empresa do setor de alimentos; e (c) tratamento e análise das informações coletadas.

O roteiro de entrevista foi aplicado, in loco, junto ao coordenador ambiental da unidade de negócios em estudo. Além disso, as informações primárias foram complementadas tendo como base fontes secundárias, tais como material institucional, relatórios anuais e balanços patrimoniais.

\section{COMPETITIVIDADE E GESTÃO AMBIENTAL}

O atual cenário competitivo é caracterizado pelo processo de globalização e por avanços tecnológicos acelerados, criando ambientes altamente dinâmicos e competitivos nos mais diversos setores. Em tal situação, as fontes convencionais de vantagem competitiva, como economias de escala, podem não se mostrar mais tão eficazes quanto eram antes. Diante dessas mudanças, prevalece um novo paradigma, em que se destacam a flexibilidade estratégica, a perspectiva global a inteligência competitiva e a inovação (Hoskisson et al, 2009). ${ }^{\text {ii }}$

Nesta nova realidade, uma adequada gestão ambiental passa a ter grande relevância no cenário competitivo empresarial. Sob o enfoque ambiental, alguns aspectos podem ser destacados. No que diz respeito à globalização, observa-se a crescente relevância não só da interdependência econômica de mercados, como também da interdependência ambiental, com destaque para o aquecimento global. No processo acelerado de mudanças tecnológicas, o alcance de vantagem competitiva pode estar atrelado a esforços inovativos, guiados pelo contexto ambiental, seja por adequação regulatória ou antecipação a questões ambientais. Isso pode ocorrer pela criação de tecnologias para processos mais "limpos", tratamento de efluentes, utilização de resíduos, matériasprimas menos poluentes, entre outros. Na definição de estratégias, as organizações precisam considerar a importância de diferentes stakeholders, tais como Governo, sociedade e comunidade local. Passa-se a considerar, inclusive, a abordagem multistakeholders, a partir de uma visão sistêmica e com ações envolvendo todas as partes interessadas.

Hoskisson et al (2009) atentam para uma perspectiva recente da administração estratégica, em que predomina a orientação do comportamento empresarial tendo em vista os três diferentes grupos de stakeholders: do mercado de capitais, do mercado de produtos e organizacionais. Para os autores, o desempenho empresarial é multidimensional, e a criação eficiente de valor deve ocorrer pelo equilíbrio do desempenho dos stakeholders, ponderando os conflitos entre diferentes grupos. Nesse sentido, o conceito de desenvolvimento sustentável pode se tornar estratégico para a empresa. ${ }^{\text {iii }}$

No que concerne ao aspecto estratégico da gestão ambiental, Porter e van der Linde (1999), ao discorrerem sobre o possível dilema entre adequação ambiental e competitividade, afirmam que a necessidade de adequação ambiental deve impulsionar inovações que levam a maior

Revista de Gestão Social e Ambiental - RGSA, São Paulo, v. 5, n. 2, p. 112-125, mai./ago. 2011. 
competitividade das empresas. Para os autores, deve-se eliminar o impasse ecologia versus economia, à medida que a adoção de práticas ambientalmente corretas não está atrelada ao mero aumento dos custos. Para os autores, inovações desenvolvidas no contexto da dinâmica competitiva podem proporcionar às organizações aumento da produtividade dos recursos, tornando-as mais competitivas. Assim, as empresas devem ampliar o enfoque, considerando o desperdício de recursos e de esforços de produção, bem como o comprometimento do valor do produto para o cliente associado à abordagem tradicional.

O novo paradigma competitivo exige que a organização transforme as estratégias ambientais em assunto da alta gerência, incorpore o impacto ambiental na questão abrangente de aumento da produtividade e competitividade, direcionando o processo decisório pelo modelo da produtividade dos recursos, e não pelo modelo de controle da poluição. Sob este novo enfoque, competitividade econômica e incremento ambiental estão diretamente relacionados, uma vez que a inovação é capaz de melhorar a qualidade e, simultaneamente, promover a redução efetiva de custos (Porter; Van Der Linde, 1999). Nesse sentido, novos conceitos têm emergido na área empresarial, com destaque para o que se denomina "triple bottom line". Seguindo tal preceito, as organizações passam a preconizar a sustentabilidade e a medição do desempenho empresarial sob três aspectos: econômico, social e ambiental. De acordo com a abordagem multistakeholder de geração de valor e competitividade, destaca-se a interação da organização com os sistemas econômico, social e natural (Brown; Dillard; Marshall, 2006).

Orsato (2002), ao discorrer sobre o posicionamento ambiental estratégico, afirma que a opção por estratégias para obter melhor desempenho empresarial depende de alguns fatores, tais como a estrutura do setor em que atua, o posicionamento da empresa no setor, os tipos de mercado que a empresa atende e suas competências internas. Considerando o foco competitivo - produto ou processo - e a fonte de vantagem competitiva - custo ou diferenciação, segundo tipologia de Porter (1996), o autor ilustra que as estratégias ambientais podem ser direcionadas por: (a) aumento de produtividade dos recursos (foco em custo e processo), por meio, por exemplo, da reutilização de resíduos e da redução de perdas no processo; (b) liderança de custo ambiental (foco em custo e produto), por meio de inovações ambientais que possam gerar produtos com baixo custo econômico e/ou ambiental; (c) transcender a conformidade legal (foco em diferenciação e processo), considerando, por exemplo, a implementação de Sistemas de Gestão Ambiental, tais como a norma ISO $14001 ;^{\text {iv }}$ (d) produtos eco-orientados (foco em diferenciação e produto), gerando produtos que possam fornecer benefícios ambientais maiores ou impor custos ambientais menores que os concorrentes ${ }^{\mathrm{v}}$.

De acordo com North (1997), há diversos benefícios associados à gestão ambiental empresarial, tais como (a) redução de custos, atrelada, por exemplo, ao uso racional de recursos (energia, matéria-prima, etc.), à reciclagem de materiais e à fabricação de subprodutos; (b) aumento das receitas, decorrente de inovações em produtos e, consequentemente, do aumento de market share, criação de novos mercados ou aumento de markup; (c) benefícios estratégicos, pela melhoria da imagem da empresa, tais como renovação do portfólio de produto, aumento da produtividade, maior comprometimento e interação entre os funcionários, melhor relacionamento com autoridades públicas e comunidade, acesso mais fácil a mercados externos, entre outros.

Barbieri (2007) aponta três perspectivas da gestão ambiental empresarial: controle e prevenção da poluição e visão estratégica. Esta última, para o autor, trata-se de uma abordagem mais avançada, em que prevalecem ações proativas e antecipatórias, com envolvimento, permanente e sistemático, da alta gerência para alcance de vantagens competitivas e incremento da competitividade. Nesta abordagem estratégica, devem existir atividades ambientais disseminadas por toda a organização e ampliação de ações e práticas ambientais ao longo de toda a cadeia produtiva. A empresa, nesse caso, deve buscar alavancar oportunidades de mercado e neutralizar ameaças decorrentes de questões ambientais. Assim, a adoção da abordagem estratégica depende exatamente da existência de tais oportunidades e/ou ameaças no mercado em que a organização está

Revista de Gestão Social e Ambiental - RGSA, São Paulo, v. 5, n. 2, p. 112-125, mai./ago. 2011. 
inserida.

As estratégias de atuação na área ambiental podem ocorrem em diferentes níveis. Em um estágio inicial, para sobrevivência empresarial, em que a empresa deve buscar a conformidade legal, que corresponde ao atendimento das exigências legais. Um segundo estágio, de conformidade normativa, diz respeito ao atendimento voluntário às normas técnicas ambientais de gestão e de processo, com eventuais certificações, sendo importante para posicionamento competitivo no mercado. Em um terceiro estágio, a empresa pode adotar postura gerencial proativa e abordar a questão ambiental de maneira integrada, considerando a avaliação dos impactos no meio ambiente, a mensuração dos custos ambientais e o princípio de melhoria contínua, buscando a ecoeficiência, por meio, por exemplo, da adoção de tecnologias mais limpas. Por fim, o econegócio, que corresponde ao quarto estágio de conformidade ambiental, em que a empresa busca se inserir em mercados ambientalmente responsáveis, com pesquisa, geração e fornecimento de produtos sustentáveis a partir de avanços tecnológicos significativos para preservação ambiental, cujo intuito é estimular, intensificar ou expandir os negócios ambientalmente responsáveis. Inclui-se neste último estágio, o fomento à biodiversidade, criação e participação em comitês para sustentabilidade (Fiesp/Ciesp, 2006)

Com base em uma revisão de literatura, Souza (2002) mostra que a gestão ambiental tem passado por um processo evolutivo nas organizações. Em maior ou menor grau, tem-se transcorrido de uma postura mais reativa, em que se destaca um "modelo de conformidade", no qual a questão ambiental é considerada uma ameaça, para uma postura mais proativa, de acordo com um "modelo estratégico", em que as empresas enxergam aspectos ambientais como oportunidades de negócio. São condicionantes de tal dinâmica alguns fatores organizacionais, tais como Governo, concorrentes, mercado, instituições e fornecedores, bem como o tipo de resposta de cada empresa. $\mathrm{O}$ autor afirma que a evolução nas estratégias ambientais nas empresas é, em geral, decorrente de: (a) regulamentação; (b) pressão da sociedade civil; (c) condições de mercado - consumidores ambientalmente mais atentos e concorrência acirrada; e (d) recursos escassos - água, energia, dinheiro, etc.

Recentemente tem-se destacado o consumidor como importante stakeholder no processo de adequação sustentável das empresas. Akatu e Ethos (2010), ao discorrerem sobre percepções e expectativas do consumidor brasileiro sobre a responsabilidade social das empresas (RSE), apontam algumas práticas ambientais destacadas como relevantes pelos consumidores. Entre elas, encontram-se: (a) a promoção de programas de informação ou educação de consumidores sobre os impactos sociais e ambientais relativos aos hábitos de consumo; (b) investimento em novas tecnologias que permitam a reciclagem pós-consumo; (c) manter programas para racionalização e otimização do consumo de água e energia; e (d) incluir critérios de responsabilidade social em seus processos de seleção e avaliação de fornecedores.

Segundo este mesmo estudo, para $65 \%$ dos consumidores entrevistados, a construção de uma imagem de empresa socialmente responsável depende da adoção de práticas ambientais, que incluem a gestão dos impactos ambientais, das inovações tecnológicas e da emissão de gases de efeito estufa (GEEs). Nesses aspectos, este estudo aponta forte discrepância entre as expectativas do consumidor e as ações de empresas brasileiras, pois apenas $35 \%$ das empresas entrevistadas adotam tais tipos de práticas (Akatu; Ethos, 2010).

De acordo com Andrade (1997), em busca de se adequar ao novo padrão competitivo, associado às exigências de se considerar aspectos ambientais na definição de estratégias, as empresas podem se posicionar em três estágios estratégicos distintos: (a) estratégia reativa, atendendo minimamente e, de maneira relutante, a uma legislação ambiental vigente, e encarando adequações ambientais como custosas e sem retorno financeiro; (b) estratégia ofensiva, buscando se antecipar aos concorrentes por meio da redução da poluição e do uso de recursos ambientais, além do exigido por lei, via mudanças incrementais em processos e produtos, percebendo, portanto, a questão ambiental como fonte de vantagem competitiva e (c) estratégia inovativa, se antecipando aos problemas ambientais futuros, buscando a excelência ambiental, a inovação em produtos e

Revista de Gestão Social e Ambiental - RGSA, São Paulo, v. 5, n. 2, p. 112-125, mai./ago. 2011. 
processos e a vinculação de questões ambientais à estratégia corporativa (Andrade, 1997).

Destacando a relevância de mecanismos de política pública que incentivem os esforços de melhoria ambiental, Porter e Van Der Linde (1999) afirmam que a regulamentação ambiental apresenta implicações competitivas. Para os autores, uma minoria de empresas apresenta postura proativa de inovação para melhoria ambiental, sendo mais frequente a observância de inovação para adequação ambiental, em resposta a mecanismos regulatórios. Assim, tal regulamentação é importante para impulsionar tais inovações. Isso se deve a algumas razões, tais como pressão sobre as empresas para geração de inovações; melhoria da qualidade ambiental; alerta às empresas sobre o uso ineficiente dos recursos e necessidade de aprimoramento tecnológico; incentivo às inovações ambientalmente corretas; promover equilíbrio competitivo, garantindo que empresas não criem vantagem competitiva a partir de ações agressivas ao meio ambiente.

A questão ambiental pode estar atrelada a estratégias empresariais em diversos aspectos. A geração de vantagem competitiva em custo, por exemplo, pode depender da adoção de práticas para melhoria ambientais que permitam economia de materiais, maiores rendimentos do processo, melhor utilização de subprodutos, menor consumo de energia e água, redução do custo de embalagens e de descarte, entre outros. Estratégias de diferenciação, por sua vez, podem ser alavancadas pela geração de produtos ambientalmente corretos e a adoção de selos que certifiquem tais características, quando este é atributo valorizado pelos clientes e reflete melhor imagem da marca.

Em estratégias de internacionalização, a adoção de melhorias ambientais também é relevante, à medida que (a) consumidores de mercados almejados valorizam práticas ambientais, o que representa um atributo relevante; (b) a exigência por produtos e processos ambientalmente corretos é frequente em muitos países, caracterizando, muitas vezes, barreiras à exportação. Processos de diversificação também podem ser impulsionados por práticas de cunho ambiental: pode-se promover a diversificação pela produção pelo aproveitamento dos resíduos antes descartados, o que resulta no aumento do portfólio de produtos e/ou criando novas linhas de produtos. Por fim, empresas que atuam em ambiente altamente inovativo e/ou que adotem a inovação como estratégia foco podem fazer uso de práticas ambientais, associando a inovação com as melhorias ambientais.

Assim, fica claro que vantagens associadas à adoção de práticas ambientalmente corretas pelas empresas é fato presente e que pode ser identificado em diversos setores. Tais vantagens podem ser oriundas de stakeholders diversos. Instituições financeiras, por exemplo, disponibilizam crédito com menores taxas de juros para empresas que comprovadamente possuem projetos de redução do impacto ambiental negativo de suas atividades. Além disso, a Bolsa de Valores de São Paulo (Bovespa, 2007) utiliza um índice para verificar a sustentabilidade de empresas (ISE). ${ }^{\text {vi }} \mathrm{A}$ partir deste índice há a sinalização e, consequentemente, valorização das ações de empresas que causam menor impacto negativo para o meio ambiente.

Outro aspecto relacionado à competitividade para empresas "amigas do meio ambiente" é a possibilidade de comercialização de créditos de carbono. Por meio deste mecanismo, empresas que lançam na atmosfera GEEs, tais como dióxido de carbono $\left(\mathrm{CO}_{2}\right)$; monóxido de carbono $(\mathrm{CO})$, metano $\left(\mathrm{CH}_{4}\right)$, entre outros, têm a possibilidade de reduzir seu impacto negativo comprando créditos de carbono de outras empresas. ${ }^{\text {vii }}$ Isso significa que empresas que mais absorvem GEEs ${ }^{\text {viii }}$ do que lançam esses gases no meio ambiente podem vender o "direito de poluir" (créditos de carbono) às demais. Portanto, a venda de créditos de carbono pode representar fator de incremento à competitividade para empresas ambientalmente corretas, elevando suas receitas.

Santin (2007) aponta que as principais vantagens potenciais para as empresas podem ser relativas a ganhos financeiros e preservação ambiental. A adequação à legislação ambiental, ou seja, estar de acordo com a Legislação ambiental vigente, evita o pagamento de multas e/ou outras penalidades para empresa, além de criar maior reputação e melhor imagem tanto em relação a seus clientes quanto em relação à sociedade.

Revista de Gestão Social e Ambiental - RGSA, São Paulo, v. 5, n. 2, p. 112-125, mai./ago. 2011. 
Outra possível estratégia está ligada à utilização de materiais reciclados, podendo gerar redução do custo de aquisição de materiais e sendo, portanto, uma das alternativas para redução de custos de produção. Soma-se a esta estratégia o reaproveitamento interno ou comercialização de resíduos. A reutilização de recursos produtivos, que antes eram descartados ou a sua comercialização, pode representar ganhos financeiros. Certos tipos de resíduos (ex.: vinhaça da cana; polpa cítrica; levedura de cerveja) necessitam de disposição adequada e/ou tratamento antes de serem descartados, e seu reaproveitamento ou comercialização podem reduzir ou anular esse tipo de custo, além de permitir aumento de receita.

Considerando a gestão ambiental estratégica ao longo da cadeia de suprimentos, de acordo com Mollenkopf et al (2010), estratégias ambientais de cadeia de suprimentos (green supply chain strategies) são aquelas relativas a esforços para minimização dos impactos negativos de firmas e suas cadeias de suprimentos no meio ambiente. Em termos amplos, os mecanismos de gestão sustentável da cadeia de suprimentos estão relacionados à obtenção de melhor desempenho ambiental, melhorando a cadeia de valor. Para alavancar vantagem competitiva, faz-se necessário o estabelecimento de alianças e parcerias entre os agentes da cadeia, dado que a abordagem de gestão da cadeia de suprimentos está relacionada a complexidade, sinergia e as interações de longo prazo.

Nesse contexto, dois aspectos podem ser destacados. Primeiramente, a montante da cadeia, a consideração da perspectiva ambiental para seleção e melhoria de fornecedores. O incentivo e a valorização de práticas ambientalmente corretas dos fornecedores podem favorecer a própria gestão ambiental interna, à medida que facilitam a obtenção de processos mais limpos, produtos menos agressivos ao meio ambiente, redução de descartes, melhor imagem da marca, entre outros. Na jusante da cadeia, por sua vez, a logística reversa pode representar importante mecanismo de gestão ambiental. ${ }^{\text {ix }}$

Fica claro, portanto, que o surgimento de um novo cenário competitivo impõe a necessidade de adoção de novas posturas pelas empresas, que, por sua vez, permitem a alavancagem de vantagem competitiva sustentável a partir de oportunidades relacionadas a melhorias ambientais. Em um contexto de gestão ambiental estratégica, organizações podem fazer uso de diversas práticas ambientais, considerando os mais distintos stakeholders, e gerando vários benefícios, podendo, inclusive, associar aspectos ambientais com ganhos financeiros e aumento de competitividade.

\section{RESULTADOS E DISCUSSÃO}

Esse estudo foi realizado em uma grande empresa multinacional de capital aberto, que iniciou suas operações no Brasil há algumas décadas, atuando, principalmente, no setor de alimentos. A unidade de negócios em estudo foi fundada em 1977 e contava, em 2009, com 1.000 colaboradores e capacidade produtiva de 145 mil toneladas por ano. O setor de atuação é a fabricação de alimentos, nos segmentos de cereais (60\% das vendas da unidade); alimentos infantis (baby food) (25\% das vendas) e linha "culinários" (sopas, temperos, caldos, etc.) (15\% das vendas). A linha cereais foi apontada, na entrevista, como a mais relevante para a unidade de negócio, por ser a principal em termos de vendas.

Os produtos são distribuídos majoritariamente no mercado nacional (99,5\% do total), com maior relevância para a região Sudeste (50\% da produção). A pesquisa de campo identificou que, para as linhas cereais e alimentos infantis, a empresa é a primeira no ranking nacional de vendas, enquanto para a linha "culinários", assume a segunda posição em vendas no Brasil. Seus principais concorrentes são empresas de grande porte, sendo elas multinacionais ou grandes corporações de capital nacional.

\subsection{Estratégia corporativa}

Em termos gerenciais corporativos, a empresa anunciou recentemente a implantação de um projeto para padronização global de seus processos de negócios e sistemas de informação. Considerando a globalização e os avanços da tecnologia da informação (TI), a empresa afirma ser

Revista de Gestão Social e Ambiental - RGSA, São Paulo, v. 5, n. 2, p. 112-125, mai./ago. 2011. 
crucial o aproveitamento de seu tamanho para aumentar sua competitividade e consolidar sua política de expansão. A ideia é alcançar a criação de "fábricas sem fronteiras", a liderança em produtos e canais de comercialização e a redução de custos pela melhor utilização da capacidade produtiva.

Assim, por meio de uma racionalização da produção, busca-se a liderança nos mercados em que a empresa atua. Ao se observar dados recentes da empresa, pode-se constatar que, em 2010, em cinco dos seis principais grandes segmentos de atuação da empresa, a presença de produtos no Brasil se faz por meio de fabricação local e por importação de outras unidades (excepcionalmente de terceiros). Isso é parte do processo de racionalização, em que plantas produtivas podem se especializar, serem mais competitivas e distribuir o produto em países vizinhos.

Em termos de crescimento interno, os dados indicam um crescimento das vendas no Brasil de cerca de $20 \%$ entre 2010 e 2009 , enquanto no mundo esse número atingiu $4 \%$. Observa-se que o posicionamento dos produtos da unidade de negócios em estudo indica consistência com as premissas estratégicas da corporação no Brasil, visto que a empresa é líder no mercado em grande parte dos segmentos em que atua.

A política de expansão global da empresa inclui processos de aquisição e aumento das vendas, especialmente em mercados emergentes, tais como América Latina e China. Além da redução de custos, o lançamento de produtos premium faz parte da estratégia, por meio de agregação de valor e a consequente redução da influência dos preços das commodities no preço final dos produtos. Para condução de sua estratégia, a empresa afirma adotar uma forte postura inovativa no mercado. Assim, duas abordagens ficam claras em termos de estratégia: por um lado, melhorar a competitividade em preço, pela otimização da produção e redução de custos; e, por outro, alavancar a competitividade em qualidade, pela agregação de valor e inovação. É preciso ressaltar que o direcionamento segundo uma ou outra abordagem depende do produto e do mercado no qual será inserido.

\subsection{Gestão ambiental empresarial}

A corporação tem definida uma política ambiental, preconizando o uso consciente dos recursos, a prevenção à poluição e o descarte apropriado dos resíduos, em consonância com os preceitos do desenvolvimento sustentável. Seus resultados são direcionados especialmente para a redução de emissão de gases de efeito estufa (GEE) e do consumo de água e energia. Tais resultados são alavancados a partir de políticas específicas, considerando, por exemplo, programas para substituição da matriz energética e política de tratamento das águas residuais dos processos.

A política ambiental está inserida em princípios empresariais, que englobam a criação de valor sustentável, a geração de lucros, o atendimento aos interesses dos consumidores, às necessidades dos colaboradores e o respeito à legislação. Isso mostra o direcionamento da estratégia segundo a abordagem dos stakeholders. Nessa visão, a empresa entende que a adoção de práticas sustentáveis, do ponto de vista ambiental e social, auxilia na redução de custos, pela racionalização do uso de recursos e substituição de matérias-primas, por exemplo, bem como no processo de agregação de valor, dado que podem ser entendidas como diferenciais pelo mercado.

Destaca-se a existência de um programa específico para área ambiental no Brasil, com projetos para educação ambiental nas escolas, conscientização ambiental de consumidores e incentivo à cooperativas de coleta de recicláveis e parcerias com agentes de distribuição, fornecimento e organizações não-governamentais. Entende-se, portanto, que a formalização da política ambiental está atrelada a política empresarial, e inclui ações junto aos stakeholders.

A sede da empresa no Brasil decidiu, em 2007, implementar um Sistema de Gestão Integrada (SGI) nas unidades brasileiras, baseado nos referenciais normativos ISO 9001 (gestão da qualidade); ISO 14001 (gestão ambiental); OHSAS 18001 (gestão de saúde e segurança) e ISO 22000 (gestão de segurança alimentar). Tal sistema veio substituir sistema próprio de gestão da empresa, desenvolvido pela matriz e implementado mundialmente. Segundo dados da pesquisa,

Revista de Gestão Social e Ambiental - RGSA, São Paulo, v. 5, n. 2, p. 112-125, mai./ago. 2011. 
“[...] a empresa no Brasil sentiu a necessidade de estar mais alinhada às práticas de mercado, no que diz respeito à gestão, implementando modelos reconhecidos internacionalmente e que evoluam de forma mais sistematizada".

O SGI na unidade em estudo teve seu início de implantação em 2008, estando, em 2009, ainda em fase de implantação. A adoção de tal sistema está de acordo com a política de padronização e de inserção em novos mercados, preconizados pela estratégia global da empresa. De fato, a adoção de sistemas padronizados de gestão em si consiste em um processo de uniformização de procedimentos; a consequente obtenção de selos, por sua vez, pode ser um facilitador de inserção em mercados, à medida que clientes utilizem tais selos no processo de seleção de produtos.

Segundo dados da empresa, na perspectiva da visão dos stakeholders para criação de valor, o desenvolvimento sustentável é considerado na cadeia produtiva, levando-se em conta aspectos sociais e ambientais. Junto aos fornecedores, tal consideração ocorre por meio de programas específicos de assistência técnica e treinamento para a produção rural, bem como de programas de fomento à pesquisa e desenvolvimento para aumento da produtividade. Entretanto, ao se verificar as exigências formais para os fornecedores da empresa, observa-se, nos aspectos ambientais, que são relativas ao cumprimento da lei, estando, portanto, no nível mínimo de adequação ambiental. Especificamente na unidade em estudo, nem mesmo as exigências de cumprimento legal são controladas pela empresa, dado que a assinatura dos termos de responsabilidade dos produtores agropecuários não é condição para compra da matéria-prima. Ademais, destaca-se que não há programas específicos para desenvolvimento de práticas ambientalmente corretas junto a fornecedores na unidade.

Segundo pesquisa de campo, a alta direção tem elevado comprometimento com a política ambiental. Esse comprometimento pode ser percebido por alguns meios: (1) reuniões de análise crítica da alta direção, com análises periódicas do desempenho ambiental; (2) provisão de recursos para implementação das ações necessárias para garantir o cumprimento da política ambiental; e (3) participação efetiva na gestão do sistema por meio de práticas específicas. A atuação da alta gerência, nesse sentido, se faz necessária até mesmo para condução da política ambiental dentro do SGI, por ser exigida pelas normas ISO.

$\mathrm{Na}$ unidade de negócios em estudo, foram identificadas duas principais práticas ambientais, implementadas há mais de dez anos, enquanto operava sistema de gestão próprio.

a) Destinação de resíduos: a gestão de resíduos na empresa ocorre por meio de métodos de reaproveitamento e reciclagem dos resíduos gerados em suas atividades. Destaca-se, nesse aspecto, a venda de materiais recicláveis para cooperativas de coleta locais, condizente com a política de apoio à reciclagem da corporação. A pesquisa de campo identificou que tal prática foi implementada pela área administrativa/financeira, principalmente em decorrência da venda dos recicláveis. $\mathrm{O}$ estímulo para sua implementação veio da necessidade de se dar destinado apropriado aos resíduos, principalmente em decorrência de exigência legal. Os resultados alcançados estão atrelados a redução de custos, pelo impedimento de autuações e consequente pagamento de multas.

b) Monitoramento ambiental: trata-se de requisito da norma ISO, no contexto de verificação e ação corretiva. A empresa tem definidos e documentados os procedimentos para monitorar e medir atividades com impacto significativo sobre o meio ambiente. A prática de monitoramento é relevante para acompanhar o desempenho da empresa e viabilizar controles operacionais condizentes com os objetivos e metas ambientais propostos; tais procedimentos devem estar de acordo com a legislação e os regulamentos ambientais definidos. O monitoramento ambiental foi implementado pela área de utilidades da empresa, e está voltado, principalmente, ao atendimento à legislação vigente e às metas do SGI. Os principais resultados alcançados, até 2009, dizem respeito, notadamente, à redução de custos, impedimento de autuações e ao cumprimento das metas ambientais (ISO 14000). 
Além disso, foi constatado que a implantação das práticas ambientais internamente não envolve a interação entre diferentes departamentos e também não depende de parcerias com outros agentes como centros de pesquisa, fornecedores, entre outros. Apesar de ações com outros stakeholders, ONGs e agentes de distribuição para práticas ambientais externas pela corporação, tais práticas são pontuais e mais relacionadas à construção de imagem da marca, não estando atrelada aos processos internos.

Destaca-se ainda que a implementação das práticas ambientais na unidade não exigiram inovações de produto e processo, estando vinculadas somente à inovação organizacional (SGI). Segundo a pesquisa de campo, considerando o SGI ainda em fase de maturação na unidade em estudo e a pré-existência de um sistema de gestão ambiental próprio, as inovações organizacionais são mais relativas à própria introdução das normas ISO no ambiente de trabalho.

Apesar da presença de um coordenador para condução de atividades de cunho ambiental na unidade, não existe representação na alta direção exclusiva para essa área. As práticas ambientais estão atreladas, internamente, à gerência da qualidade, à área administrativa ou aos setores de apoio técnico.

O entrevistado ressaltou ainda que a relativa imaturidade do SGI na unidade implica avaliação de poucos quesitos, especialmente consumo de água e energia, sem a existência de programas específicos que permitam uma redução de tais valores. São estes os dois únicos indicadores que devem ser reportados à corporação, direcionando a abordagem ambiental. Ao ser questionado sobre a existência de ações para controle de pontos críticos de gestão ambiental, o entrevistado reforçou que as ações existentes dizem respeito, principalmente, aos dois indicadores de reporte.

Projetos e medidas pró-ativas, por exemplo, para prevenção de vazamentos hidráulicos (por meio de um programa de manutenção preventiva) poderiam facilitar o alcance de metas definidas para o consumo de água, mas inexistem na unidade em estudo. A restrição de recursos para a área também foi apontada como uma dificuldade para a criação e implantação de novos projetos e medidas ambientais. A própria definição de metas modestas para redução nos consumos de água e energia, na implementação do SGI, pode estar atrelada a tais problemas: a relativa escassez de recursos e a inexistência de programas específicos poderiam dificultar o alcance de resultados mais ousados.

Outro fator a ser destacado diz respeito a práticas produtivas, o que acarreta alguns problemas, dentre os quais o alto volume de resíduos em solo e a perda de produto. Do ponto de vista ambiental, tais resíduos devem ter tratamento e/ou destino apropriado. $\mathrm{Na}$ empresa, muitas vezes tais resíduos são vendidos como subproduto (farinha de varredura) para fabricantes de ração animal. Observa-se, então, a necessidade de práticas mais adequadas, pois a redução da varredura permitiria ganhos maiores à empresa, comprometidos pela perda de valor associada à venda como subproduto, seja pela própria necessidade de tratamento adequado de tais resíduos.

A redução da varredura, assim como dos consumos de água e energia, é objetivo do SGI, mas também não possui programas específicos para tal. Segundo entrevista: "alguns projetos existentes foram conectados ao objetivo de redução de varredura, mas não foram criados para este fim; na verdade, são projetos definidos com o foco de redução do custo da não qualidade. Eventualmente, sua execução pode impactar na redução da varredura." Assim, a redução da varredura é um meio para o projeto, e não um fim, não estando, portanto, diretamente vinculado aos aspectos ambientais. Isso indica que a redução de custos da não qualidade pode acontecer via redução da varredura ou por outros meios, que não impliquem melhorias ambientais.

\subsection{Gestão ambiental e estratégia empresarial}

De uma maneira geral, observou-se preocupação na empresa em atender aos requisitos legais e a normas do SGI, para obter a certificação e atender as exigências corporativas. A partir deste estudo, foi possível apontar dois principais focos das práticas ambientais nas empresas: a

Revista de Gestão Social e Ambiental - RGSA, São Paulo, v. 5, n. 2, p. 112-125, mai./ago. 2011. 
implementação do SGI e o atendimento às exigências legais.

Conforme ilustrado na figura 1, com base em tais aspectos, a empresa busca: (1) redução de custos, seja pela prevenção de multas ou pela redução de perdas em processo (especificamente, de água e energia); (2) atendimento às necessidades da corporação, não somente por operar em conformidade com a lei, como também por viabilizar a padronização dos negócios no mundo e por alcançar a certificação, pela imposição do SGI à unidade em estudo; (3) melhoria da imagem da marca, atrelada ao cumprimento da lei e à certificação ISO. Pelo alcance de tais resultados, a empresa pode tirar proveito de maior inserção no mercado de atuação ou almejar a inserção em outros mercados, pelos custos menores ou pela melhor imagem da marca. De certa forma, observase, portanto, alguma sincronia entre a estratégia global de expansão e as ações ambientais na empresa (Figura 1).

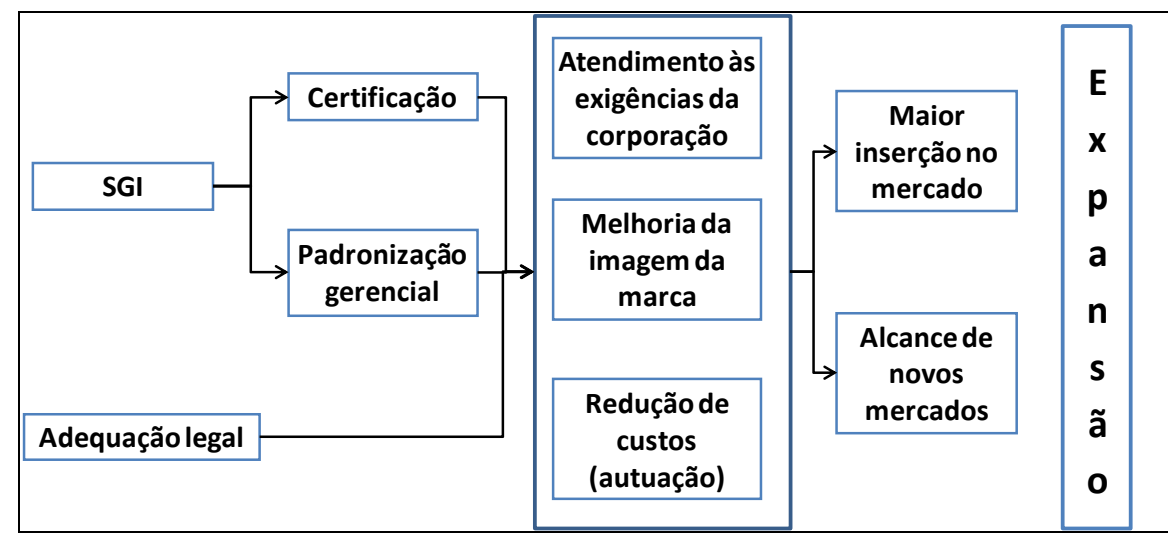

Figura 1: Sincronia entre ações ambientais e estratégia empresarial global.

Fonte: Elaboração própria.

Apesar da sincronia observada, não se pode afirmar que a estratégia competitiva tem como um dos pilares a gestão ambiental. Ainda que ela faça parte do SGI, as ações e melhorias ambientais não se mostram direcionadoras na unidade em estudo. Ao invés disso, a pesquisa mostrou que o interesse está majoritariamente voltado para o cumprimento da lei e alcance das certificações. Dessa forma, observa-se a sincronia, e não a sinergia, entre estratégia e gestão ambiental, dado que os aspectos ambientais não são conduzidos para alavancagem da estratégia competitiva da unidade (figura 2).

Isso pode estar atrelado à imposição do sistema de gestão ambiental na unidade de negócios pela empresa. O direcionamento top down, nesse caso, parece não ter sido acompanhado de uma adequação e conscientização interna, o que dificulta a efetividade de melhorias ambientais. Entende-se que a unidade de negócios em estudo encontra-se em estágio inicial de atuação ambiental (conformidade legal), pois a adoção de práticas não exigidas por lei, nesse caso, não se fez de maneira voluntária, e sim por imposição do grupo.

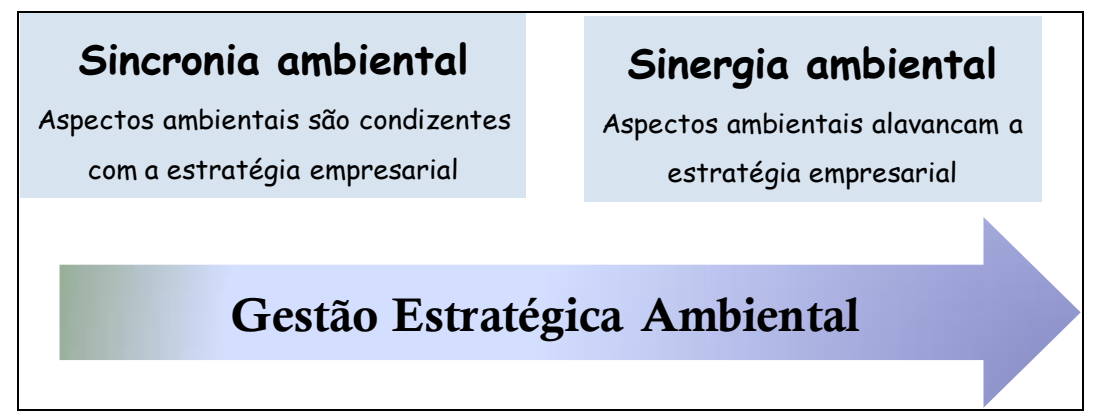

Figura 2: Da sincronia à sinergia ambiental na empresa.

Fonte: Elaborado pelos autores. 
Além disso, destaca-se que os objetivos ambientais não estão atrelados a métodos de melhoria e projetos específicos. Muitas vezes, os objetivos são formalizados, mas não existem programas de melhoria e parcerias para condução de ações proativas e de longo prazo. Isso pode comprometer a efetividade das práticas ambientais, uma vez que não são construídos "caminhos" para se alcançar melhorias. Isso fica claro quando se considera o caso dos fornecedores agropecuários: há uma definição formal do que se espera em termos ambientais, mas não existem, por exemplo, a sistematização de melhores práticas ambientais ou a criação de projetos de parceria para adequação ambiental dos fornecedores.

A carência de inovações em produto e processo para melhoria ambiental, por sua vez, inviabiliza a redução dos custos de adoção de melhorias ambientais. Vale lembrar, neste aspecto, que a inovação se faz necessária para alcance de competitividade ambiental, conforme preconiza a teoria. Sem inovação, as práticas ambientais acabam por se traduzir em custos para a empresa, sendo, portanto, direcionadas ao mínimo necessário. Nesse caso, a contrapartida dos custos ambientais fica atrelada à redução do consumo de recursos de entrada e ao aproveitamento de resíduos, bem como à conformidade legal e corporativa.

Destaca-se, por fim, a importância de interação entre áreas internas e com agentes externos para alcance de melhorias ambientais, algo pouco observado na pesquisa de campo. A coordenação interna e ao longo da cadeia de suprimentos poderia levar a ganhos em aspectos ambientais, aproveitando conhecimento, reduzindo esforços, além de resultar em maior comprometimento dos agentes.

\section{CONSIDERAÇÕES FINAIS}

Com base nesta pesquisa, foi possível constatar alguns aspectos relevantes da gestão ambiental na unidade em estudo. Primeiramente, observa-se que a busca por selos e certificações ambientais se caracteriza como um mecanismo para redução de custos e padronização de processos na empresa em estudo.

Entende-se, por um lado, que inovações em processo, maior eficiência e gestão de resíduos, e produto, novos ingredientes e embalagens, para condução de práticas ambientalmente sustentáveis se fazem necessárias para atender a novas tendências de consumo. Por outro, a definição de diretrizes e projetos específicos para a área ambiental, bem como o estabelecimento de métodos para alcance de melhorias nesse aspecto, se mostram essenciais para o alcance da sinergia ambiental na empresa.

Por fim, ainda que a implantação de sistemas de gestão dependa de procedimentos top down, sua adoção eficaz está sujeita à conscientização e adequação das unidades locais. Atrelada a isso, destaca-se a pouca interação entre áreas internas com os agentes externos para alcance de melhorias ambientais, o que pode barrar ganhos de esforços para melhorias ambientais. Entende-se que somente a partir de adoção de tais mecanismos, se torna possível aproveitar ao máximo os benefícios em termos ambientais, promovendo melhorias, alcance de vantagens competitivas sustentáveis e ganhos de competitividade, nesse aspecto.

\section{REFERÊNCIAS}

Akatu; Ethos (2010). Instituto de empresas e responsabilidade social. O consumidor brasileiro e a sustentabilidade: atitudes e comportamentos frente ao consumo consciente, percepções $e$ expectativas sobre a RSE. Pesquisa 2010. Disponível em: <http://www.akatu.org.br>. Acesso em 05 jan 2011.

Andrade, J. C. S. (mai./ago.1997) Desenvolvimento sustentado e competitividade: tipos de 
estratégias ambientais empresariais. In: Tecbahia Revista Baiana Tecnol., Camaçari, 12(2).

Barbieri, J. C. (2007) Gestão ambiental empresarial: conceitos, modelos e instrumentos. (2 ed.) São Paulo: Saraiva.

Bovespa. (2007) Índice de Sustentabilidade Empresarial - ISE. Recuperado em 10 nov.2007, de: $<$ http://www.bovespa.com.br/Principal.asp>.

Brown, D., Dillard, J., Marshall, R. S.(2006) Triple bottom line: a business metaphor for social construct. Document de Treball num. 06/2 . Departament d'Economia de l'Empresa / Universitat Autònoma de Barcelona.

Farrell, G., Lukesch, R., Thirion, S. (junho de 2000) Competitividade ambiental: conceber uma estratégia de desenvolvimento territorial à luz da experiência Leader. Observatório Europeu Leader. Bruxelas. Recuperado em 20 fev.2010, de: <http://www.fao.org/sard/static/leader/pt/biblio/environment.pdf> .

Fiesp/Ciesp. Federação e Centro das Indústrias do Estado de São Paulo. (2006) Agenda da conformidade ambiental da indústria paulista. Recuperado em 10 nov. 2011, de: <www.fiesp.org.br>.

Fiesp, Ital. (2010) Brazil food trends 2020. São Paulo. Recuperado em 20 abr. 2011, de: <fiesp.com.br/agronegocio/default.aspx> .

Gvces/Fgv. Centro de Estudos em Sustentabilidade da Fundação Getúlio Vargas. ISE Bovespa. Recuperado em 12 jan.2011, de: www.ces.fgvsp.br .

Hoskisson, R.E., Hitt, M. A., Ireland, R.D., Harrison, J.S.(2009) Estratégia competitiva. São Paulo: Cengage Learning.

Ibge(2008) Instituto Brasileiro de Geografia e Estatística. (2008) Pesquisa industrial anual empresa. Recuperado em 15 abr. 2011, de: www.sidra.ibge.gov.br> .

Mollenkopf, D., Stolze, H., Tate, W. L., Ueltschy, M.(2010) Green, lean and global supply chains. International Journal of Physical Distribution \& Logistics Management, 40(1/2).

North, K. (1997) Environmental business management: an introduction (second edition). Geneva: International Labour Office.

Novaes, A. G. (2007) Logística e gerenciamento da cadeia de distribuição. Estratégia, operação e avaliação. (3 ed.) Rio de Janeiro: Elsevier.

Orsato, R. J.(nov.dez.2002) Posicionamento ambiental estratégico. Identificando quando vale a pena investir no verde. Revista Eletrônica de Administração. REAd - Edição Especial 30, 8(6).

Porter, M., Van Der Linde, C.(1999) Verde e competitivo: acabando com o impasse. In: Porter, M. Competição: estratégias competitivas essenciais. Rio de Janeiro: Campus.

Porter, M. (Nov/Dec, 1996) What is strategy? Harvard Business Review.

Santin, M. F. C. L.(2007) Os impactos da demanda por crédito de carbono sobre o mercado de certificações de reduções de emissões no Brasil, no âmbito do protocolo de Quioto. Porto Alegre: Dissertação de Mestrado. Pontifícia Universidade Católica do Rio Grande do Sul, RS, 
Brasil.

Souza, R. S. (nov-dez 2002) Evolução e condicionantes da gestão ambiental nas empresas. Revista Eletrônica de Administração. REAd - Edição Especial 30, 8(6).

Weber, P. S. (1999) A gestão ambiental na empresa. Revista Sanare. 12. Recuperado em 20 jun. 2007, de: <http://www.ambientebrasil.com.br>.

Data do recebimento do artigo: 16/04/2011

Data do aceite de publicação: 02/08/2011

i Segundo Farrell, Lukesch e Thirion (2000, p. 5), a competitividade ambiental pode ser definida como a "[...]capacidade dos agentes de sublinhar a importância do seu ambiente tornando-o num elemento distintivo do seu território, assegurando ao mesmo tempo a preservação e a renovação dos recursos naturais e patrimoniais".

ii Para os autores, a vantagem competitiva é obtida com a criação e execução de estratégias distintas e que criam mais valor que as concorrentes, gerando, portanto, maiores retornos. Porter (1996), por sua vez, enfatiza que a estratégia só existe quando sua essência está vinculada às vantagens competitivas sustentáveis, cujos diferenciais em relação aos concorrentes possam ser preservados.

iii $\mathrm{O}$ desenvolvimento sustentável existe quando a empresa cresce sem esgotar o ambiente natural e sem produzir danos à sociedade (Hoskisson et al, 2009).

iv Segundo Barbieri (2007), um Sistema de Gestão Ambiental (SGA) representa um conjunto de práticas e de atividades técnicas e administrativas interrelacionadas, que envolvem: comprometimento da alta gerência; definição de uma política ambiental; avaliação de impactos ambientais; definição de metas; acompanhamento e avaliação. Exemplo de SGA é aquele preconizado nas normas da série ISO 14000. É importante ressaltar que os SGAs não são exigência legal, e sim, normas voluntárias, que podem incrementar a competitividade de empresas que os adota. Nesse sentido, são processos de autorregulamentação, que podem ser exigidos por outras organizações (clientes) e/ou consumidores finais em determinados mercados.

${ }^{\vee}$ Para este último tipo de estratégia, os consumidores devem estar dispostos a pagar pelos benefícios ambientais; deve ser possível passar informações confiáveis aos consumidores, por meio de selos e certificações, por exemplo; a diferenciação deve ser difícil de ser imitada pelos concorrentes para gerar vantagem competitiva sustentável (Orsato, 2002).

${ }^{\text {vi }}$ O ISE - Índice de Sustentabilidade Empresarial - consiste em medida de desempenho empresarial que considera a sustentabilidade corporativa, baseada na eficiência econômica, no equilíbrio ambiental, na justiça social e na governança corporativa (Bovespa, 2007; Gvces / Fgv, 2011).

vii As metas e prazos de redução de GEEs, bem como os países com compromissos de redução de emissões, foram definidos em acordo internacional - Protocolo de Quioto, 1997.

viii A absorção de GEE da atmosfera é feita por meio de sumidouros, a exemplo das florestas.

${ }^{\text {ix }}$ Segundo Novaes (2007), a logística reversa trata dos fluxos de materiais desde os pontos de consumo até seus pontos de origem, tendo como objetivos recuperar valor e/ou proporcionar disposição adequada aos materiais. Trata-se de atividades pós-consumo ou pós-venda, permitindo redução de custos em decorrência de economias de matérias-primas e reaproveitamento de materiais, cumprimento a regulamentações (ex. coleta de embalagens de agrotóxicos), além de alavancar marketing ambiental ("green marketing") e melhorar a imagem da empresa.

Revista de Gestão Social e Ambiental - RGSA, São Paulo, v. 5, n. 2, p. 112-125, mai./ago. 2011. 